\title{
Higher education for sustainable development: actioning the global goals in policy, curriculum and practice
}

\author{
I. Franco ${ }^{1} \cdot$ O. Saito ${ }^{1} \cdot$ P. Vaughter $^{1} \cdot$ J. Whereat $^{2} \cdot$ N. Kanie ${ }^{1} \cdot$ K. Takemoto $^{1}$
}

Received: 27 March 2018 / Accepted: 4 September 2018

(c) Springer Japan KK, part of Springer Nature 2018

\begin{abstract}
Higher education for sustainable development (HEfSD) is being significantly shaped by the global sustainability agenda. Many higher education institutions, responsible for equipping the next generation of sustainability leaders with knowledge and essential skills, proactively try to action the sustainable development goals (SDGs) in HEfSD policy, curriculum and practice through scattered and isolated initiatives. Yet, these attempts are not strategically supported by a governing approach to HEfSD or coordinated effectively to tackle social and environmental sustainability. These predicaments not only widen the gap between HEfSD policy, curriculum and practice but also exacerbate the complexities between human and environmental interactions compromising overall sustainability. However, these efforts represent a potential for actioning the Global Agenda for Sustainable Development. Based on a qualitative research strategy, theory building methodology and various methodological techniques (surveys, policy and literature review, group and individual interviews), this research suggests that the advancement of HEfSD in policy, curriculum and practice depends largely on a better understanding of existing gaps, target areas, commonalities and differences across regional HEfSD agendas. This will hopefully provide higher education institutions and their stakeholders across regions with some conceptual and practical tools to consider strategically how HEfSD can successfully be integrated into policy, curriculum and practice in alignment with SDGs and with the overall mandate of the Global Agenda for Sustainable Development.
\end{abstract}

Keywords Higher education for sustainable development $\cdot$ Sustainability $\cdot$ Sustainable development goals (SDGs) $\cdot$ Policy $\cdot$ Curriculum $\cdot$ Stakeholders

\section{Introduction}

A shift in Higher Education for Sustainable Development (hereafter HEfSD) policy, curriculum and practice is required around the globe for higher education to be in alignment with the global sustainability agenda. Based on theory building, as the governing methodological approach to this research, this study increases our understanding of the

Handled by Gordana Kranjac-Berisavljevic, University for Development Studies, Ghana.

I. Franco

connect@drisabelfranco.com; franco@unu.edu

1 United Nations University Institute for the Advanced Study of Sustainability, 5 Chome-53-70 Jingumae, Shibuya, Tokyo 150-8925, Japan

2 School of Humanities and Social Sciences, The University of Queensland, Brisbane, Australia current status of how HEfSD aligns with the SDGs and identifies limiting factors that impede higher education institutions and their stakeholders from translating HEfSD rhetoric into policy, curriculum and practice in relation to the SDGs.

A major transformation in higher education needs to occur across all disciplines and levels of study (Barth and Reickmann 2012; García-González et al. 2017). As Boron et al. (2017, p 38) indicates "The ultimate purpose of academic teaching programs orientated around 'sustain-ability' is to support the practical attainment of a sustainable future for industry, business and society". At the present, many higher education institutions tend to 'embellish and serve' sustainability precepts, rather than challenge or fully implement them (Hall et al. 2010).

More than ever higher education institutions and their stakeholders, that is, students, staff, scholars, administration and management, research communities, alumni, businesses, social movements, consumer organizations, governments and professional associations (Jongbloed et al. 2008) need to 
rethink the notion of HEfSD in alignment with the Sustainable Development Goals (SDGs) which are both an approach to sustainable development and a tool for addressing global problems in a collaborative (United Nations 2015; Saito et al. 2017; Kanie and Biermann 2017; Yonehara et al. 2017) and interconnected (O'Byrne et al. 2015) manner. Aligning HEfSD agendas with the SDGs will hopefully provide more guidance for relevant HEfSD policy, curriculum and practice in the future (Siraj-Blatchford and Pramling-Samuelsson 2016). Shephard (2015) defines HEfSD as an approach to education aimed to 'respond to societal expectations to address environmental, social, cultural and economic issues that threaten the sustainability of life on Earth'. However, our definition goes beyond this statement. HEfSD is here understood as an impact sustainability approach driven by higher education institutions themselves, or in collaboration with external stakeholders (governments, industry, civil society organizations), to tackle pressing sustainability issues emerging in the achievement of the Sustainable Development Goals (SDGs). The importance of HEfSD is paramount. Higher education institutions are playing a key role in fostering sustainable social and environmental transformations (Cortese 2003; Leal Filho 2011). It is also their social responsibility to help students and the broader community acquire competences for sustainable development (Lozano et al. 2015). Hence, the significance of exploring the achievement of the SDGs in the context of higher education, carefully.

Governance aspects of HEfSD, the lack of a governing approach to HEfSD, and issues around social and environmental interlinkages are key findings derived from this study. This research also builds knowledge upon existing scholarly debates on HEfSD by identifying commonalities, differences and lessons to be learned and exchanged across regions, namely the Americas, Asia and the Pacific, Africa and Europe.

The research reported in this article begins with a review of current debates within HEfSD, both in the scholarship and policy. It then presents research findings on the status of HEfSD in alignment with SDGs across four regions. The article finishes by drawing conclusions and identifying gaps for further research in this field.

\section{Literature review}

The notion of Higher Education for Sustainable Development (HEfSD) is becoming a mainstream in scholarship. There is an increasing debate, both in the literature and at the policy level, about the role of higher education institutions in addressing the complexities across human and environmental interactions globally. By the start of the UNESCO Decade of Education for Sustainable Development
(2005-2014) (UNESCO 2014), universities had adhered to several approaches to rethink sustainable development. Brundtland (1987) became the baseline of many sustainable development approaches to date: "Meet(ing) the needs of the present without compromising the ability of future generations to meet their own needs". Based on this foundation, the Triple Bottom Line was later introduced into the field of sustainability and subsequently Education for Sustainable Development (ESD) - including HEfSD — to encourage the present generation to meet their needs by keeping economic, social and environmental domains in a permanent equilibrium (Arima 2009). Following these precepts, the Halifax Declaration (Dalhousie University 1991) later mandated a real commitment to sustainability in higher education by teaching and practicing sustainable development principles. Thus, the overall objective of the decade was to incorporate the sustainability values and policy into all aspects of learning, and thus, to foster behavioral changes in view of a more sustainable society (Yarime et al. 2012).

Over the past four decades, the average number of academic articles examining HEfSD increased from 1 per year from 1970 to 1989 (20 total), 5.1 per year in 1990-2004 (77 total) and 13.2 per year in 2005-2013 (118 total). Within these respective time periods there seem to be three distinct spikes in output: first, in the mid-1970s; second, in the late 1990s; and third, from 2005 to present (Aikens et al. 2016). This trend shows that HEfSD policy is being widely researched and investigation in this field is likely to continue increasing in number of publications in the coming years (Avila and Leger, 2005; Azman et al. 2010; Blass et al. 2010; Hashimshony and Haina 2006; Snyder 2006; VincentLancrin 2006; Amatariyakul and Tesaputa 2009; Steinfeld and Mino 2009; Milutinović and Nikolić 2014; Vaughter et al. 2016).

Yet, limited attention has been paid to curriculum (Miller 2003; Ritzen 2006; Naeem and Peach 2011; Stephens 2011; Duderstadt 2012; Inayatullah et al. 2013) and HEfSD practice (McNay 1992; Conway 2003; Blass et al. 2010; Duderstadt 2012; Franco 2014) and questions on how stakeholders can foster HEfSD policy, curriculum and practice in alignment with the Global Agenda for Sustainable Development remain unanswered (Comm and Mathaisel 2008; Vaughter et al. 2013; Milutinović and Nikolić 2014; Lozano et al. 2015; García-González et al. 2017).

Similar studies to explore the global context of HEfSD have been conducted both in the scholarship and at the policy level (Molderez and Fonseca 2018; Caniglia et al. 2018). Lozano-Garcia and Huisingh (2006), for instance, undertook a compilation of transdisciplinary studies across regions grouped into five (5) categories, namely higher education and regional applications of sustainability; teaching sustainable development and environmental education; approaches to and tools for education for sustainable development; 
implementing sustainable development and reporting within academic institutions and faculty-specific approaches to education for sustainable development. Yet, this compilation does not fully align empirical research findings with any global sustainability mandates.

At the policy level, a case in point is the guidelines on 'Sustainability Science in Research and Education' (UNESCO 2015). Based on a framework for the co-design, coproduction and co-implementation of HEfSD, these guidelines provide higher education institutions with policy recommendations on how to action sustainability science in higher education. Enhancing interdependencies; better understanding of local contexts and values; further development of the interfaces between science, policy and society; transformation of the higher education system to fully integrate sustainability in both policy and practice, and fostering partnerships for sustainability are some of the recommendations drawn from this policy report. Building on this foundation, more recently, UNESCO (2017) launched the 'Practical Guidelines to Apply Sustainability Science Frameworks'. The model presented in the guidelines enables sustainability science integration into HEfSD. The framework is a tool to implement sustainability science and generate dialogue amongst various stakeholders. It consists of five main steps: co-realization of a common project, co-envisioning of a future society, co-shaping into an envisioned future society, co-implementation, and monitoring and evaluation. The first four steps are carried out within a participatory process amongst stakeholders. This participatory model fosters cooperation and integration to assist stakeholders in adapting to changing circumstances and building stakeholder ownership along the process of sustainability science implementation (UNESCO 2017).

Despite the plethora of policy recommendations and studies, higher education institutions face enormous challenges to translate HEfSD rhetoric into policy, curriculum and practice. A review of selected Canadian universities, for example, reported that higher education institutions are "firmly embedding the objectives of sustainability in the planning framework for the institution as a whole" (Vaughter et al. 2016, p 24). However, this approach has been criticized, as sustainability policy should not only limit to environmental aims but as a "solution to environmental degradation, and as well as socio-cultural degradation" (Aikens et al. 2016, p 341). Milutinović and Nikolić (2014, p 108) add that "higher education does not fully understand the true nature of the challenge and that sustainable development is still considered as an innovative idea in most universities, and has not yet permeated all disciplines, scholars, and university leaders'. Although HEfSD is being widely debated, issues on how to move from HEfSD rhetoric to policy, curriculum and practice and in alignment with the global sustainability agenda remain under-investigated.

\section{Methodology}

A qualitative strategy has been applied to this study. Thus, this investigation involved the combination of a number of qualitative methods and techniques, reducing methodological limitations (Singleton and Straits 2010). For the purpose of this research, triangulation of data sources and methods was applied to increase the reliability of the data collected (Yin 2009). Surveys, individual interviews, literature review, focus groups, field observations and policy analysis were some of the techniques applied. Data were initially collected from the literature and policy review.

The review was aimed to undertake analysis of secondary sources on global perspectives on higher education and research for sustainable development. Both scholarship and policy analyses were conducted. Overall seventy (70) manuscripts were reviewed, comprising journal articles, book chapters, policy documents and reports. Out of seventy (70), only around sixty (60) sources were considered relevant for the scope of this research. A more specific selection of sources was undertaken whilst conducting data analysis. Various databases were consulted such as Web of Science, ERIC and ProQuest. The review was also undertaken based on the following Boolean search categories to facilitate the selection of relevant sources: 'trends and themes on higher education and research for sustainable development', 'sustainability policy in higher education and research', 'HEfSD and research' and 'case studies in HEfSD'. Whilst former categories helped us identify relevant themes globally, the latter assisted us in identifying regional gaps that were later triangulated against primary sources. Policy analysis was also pivotal in conducting this review. This analysis encompassed international mandates and sustainability policy statements across participant higher education institutions. It also involved the review of international policy frameworks, influencing the current debate on HEfSD.

Researchers were also interested in hearing the perspectives and evaluations of various Regional Centres of Expertise (RCE's) on Education for Sustainable Development's focal points and stakeholders to form a composite picture of target areas and HEfSD gaps. An RCE is a network of education institutions-including higher education institutions-that in collaboration with stakeholders advocate for fostering Education for Sustainable Development (RCE Network 2018). Twenty-eight (28) RCEs' focal points participated in a global survey (see Graph 1). Two (2) focus groups and seven (7) individual interviews were conducted. The survey was translated into three languages, namely English, Spanish and Portuguese, to increase our understanding of the context of HEfSD in non-Englishspeaking countries. RCE members' background varies. 


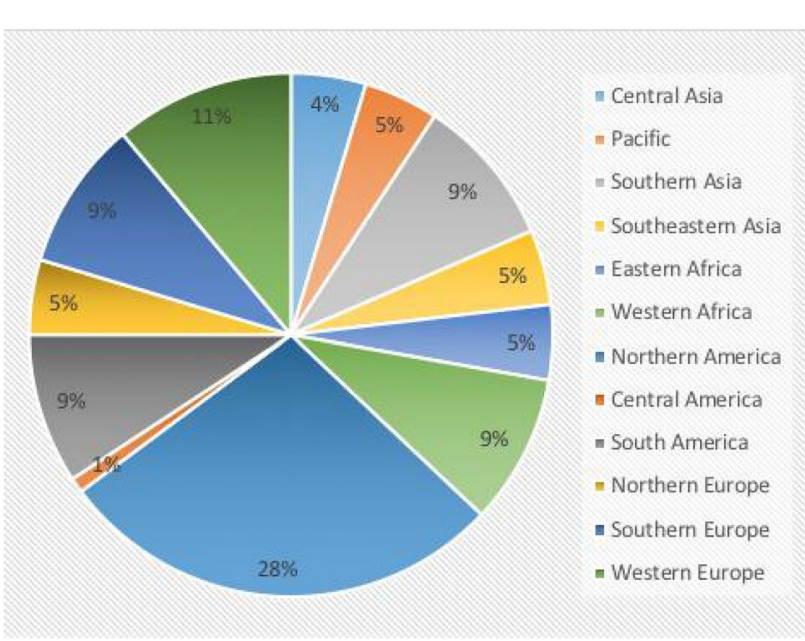

Graph 1 Global survey participants' infographics

Interviewees consisted of academics and professionals at higher education institutions. Likewise, a group of government, private sector and NGO representatives involved in their respective RCEs were also interviewed. Non-academic interviewees did not necessarily have a background in sustainability. Instead, they were project managers, trainers and government officials interested in exploring collaboration opportunities to achieve overall sustainability.

Participants' background from higher education institutions varied from practitioners, lecturers, researchers and representatives to senior executive teams engaged in sustainability science, education and practice at higher education institutions. Eight (8) participants identified themselves as civil society actors, two (2) as government representatives and two (2) as corporate actors. These actors collaborate actively with higher education institutions. The global survey showed a high participation from stakeholders from Northern America, twenty-eight percent (28\%), followed by Western Europe, eleven percent (11\%). Survey results showed low participation from Central America at one percent (1\%) (Graph 1).

\section{Data collection}

Researchers first conducted a review of the scholarship and policy to identify current themes and gaps in HEfSD. The review also documented case studies in four geographical areas (Asia and the Pacific, Americas, Africa and Europe) providing the research team with a better understanding of existing debates and gaps at the regional level. This review also helped to triangulate data from the global survey and interviews with RCE focal points and stakeholders. These data collection techniques were applied to explore the perceptions of RCEs and stakeholders and increased understanding of existing target areas and HEfSD gaps. Participants were also asked to share their perceptions on current HEfSD target areas and gaps and to list existing projects and initiatives in alignment with the SDGs. Gaps are those areas in relation to the SDGs in which RCEs and their stakeholders did not report any active project or activity. Target areas are those in which RCEs and stakeholders report at least one (1) initiative in relation to the topic.

\section{Data analysis}

The qualitative research strategy sought to inductively build new theory concerning HEfSD target areas and gaps. Theory building is an appropriate methodology as even though each of the regions explored has an extensive data and literature behind it and there is little known about how they intersect when consciously brought together. A qualitative strategy is needed to tease out these interactive links and identify HEfSD gaps and targeted areas, as well as to tease out the difference between perception and reality of those working in the field.

As such, our data analysis followed procedures for inductive theory building from each region as prescribed by Braun and Clarke's (2006) thematic analysis, and Yin's (2003) chain of evidence method to analyze data (see also Eisenhardt 1989). The chain of evidence method calls for clear links in moving from data to theory. Theory building is a process of data reduction based on cause-effect evidence. The process was to first group data into regions based on (1) features of the HEfSD approach in the form of projects and in alignment with SDGs and (2) subjective reactions of RCEs focal points and stakeholders and scholarly debates. From these two sets of themes researchers then induced theoretical inferences of cause-effect between features, projects and subjective reactions. Tables 1, 2, 3 and 4 record the data from this inductive theory-building process. In each table, the second column shows projects relevant to the region and in alignment with SDGs. Typically, these data came from surveys, interviews and focus groups.

The third column then shared quotes relevant to stating existing projects, citations of relevant scholarly literature and the subjective reactions of a diverse array of RCE focal points and stakeholders, which reflected how they thought about the existing HEfSD approach within their RCEs, as well as trends and gaps in the regions in which they are immersed. Quotes were selected which conveyed reflections and views towards existing HEfSD target areas and gaps. Participants' perceptions on HEfSD did differ across regions. However, commonalities were also found. Focal points across regions agree that various SDGs are widely targeted in higher education, specifically SDGs 4, 11, 12 and 15 . However, they also reported that major gaps remain in the achievement of SDGs 1, 2, 3 and 10 in HEfSD. More 


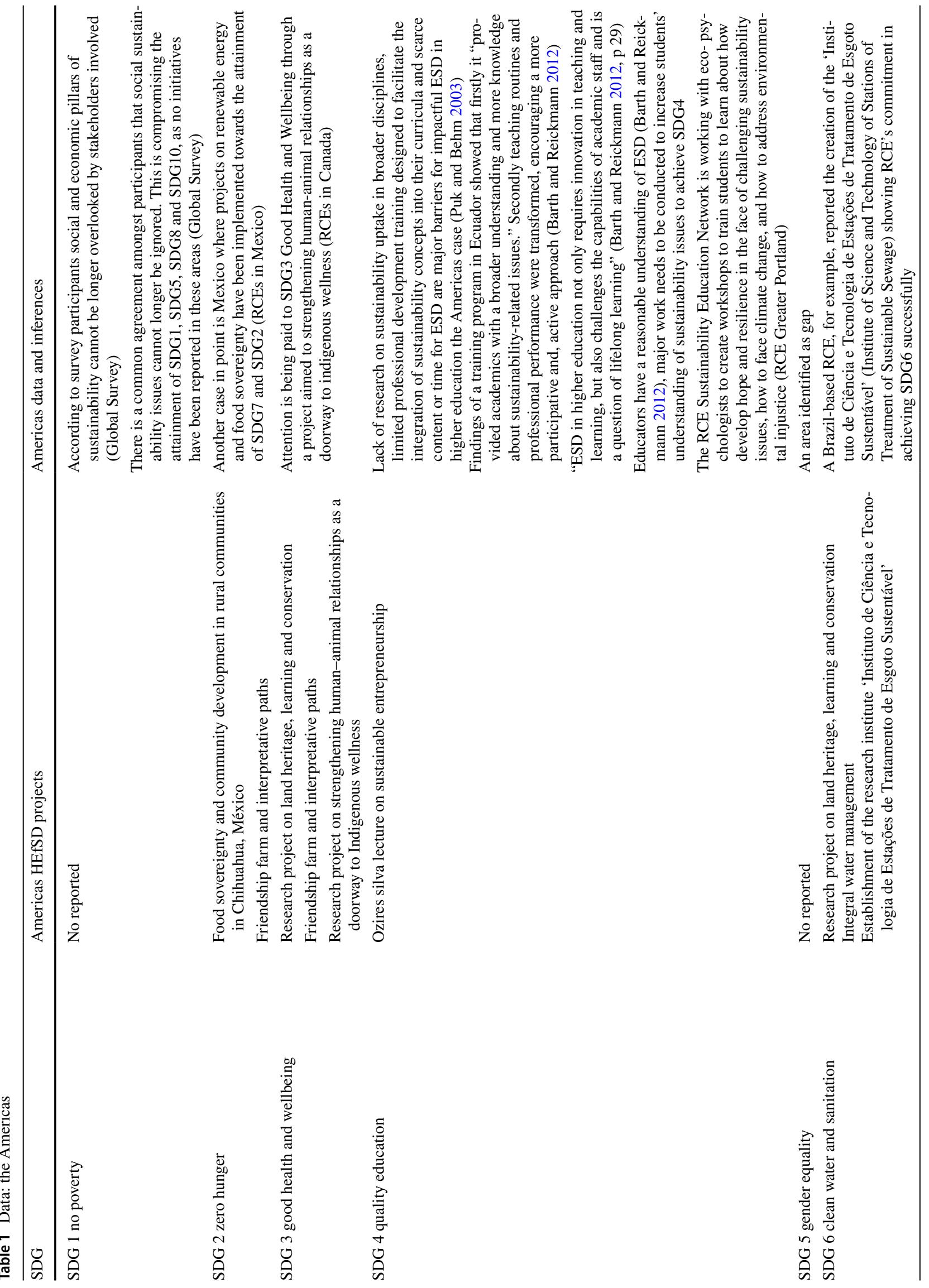




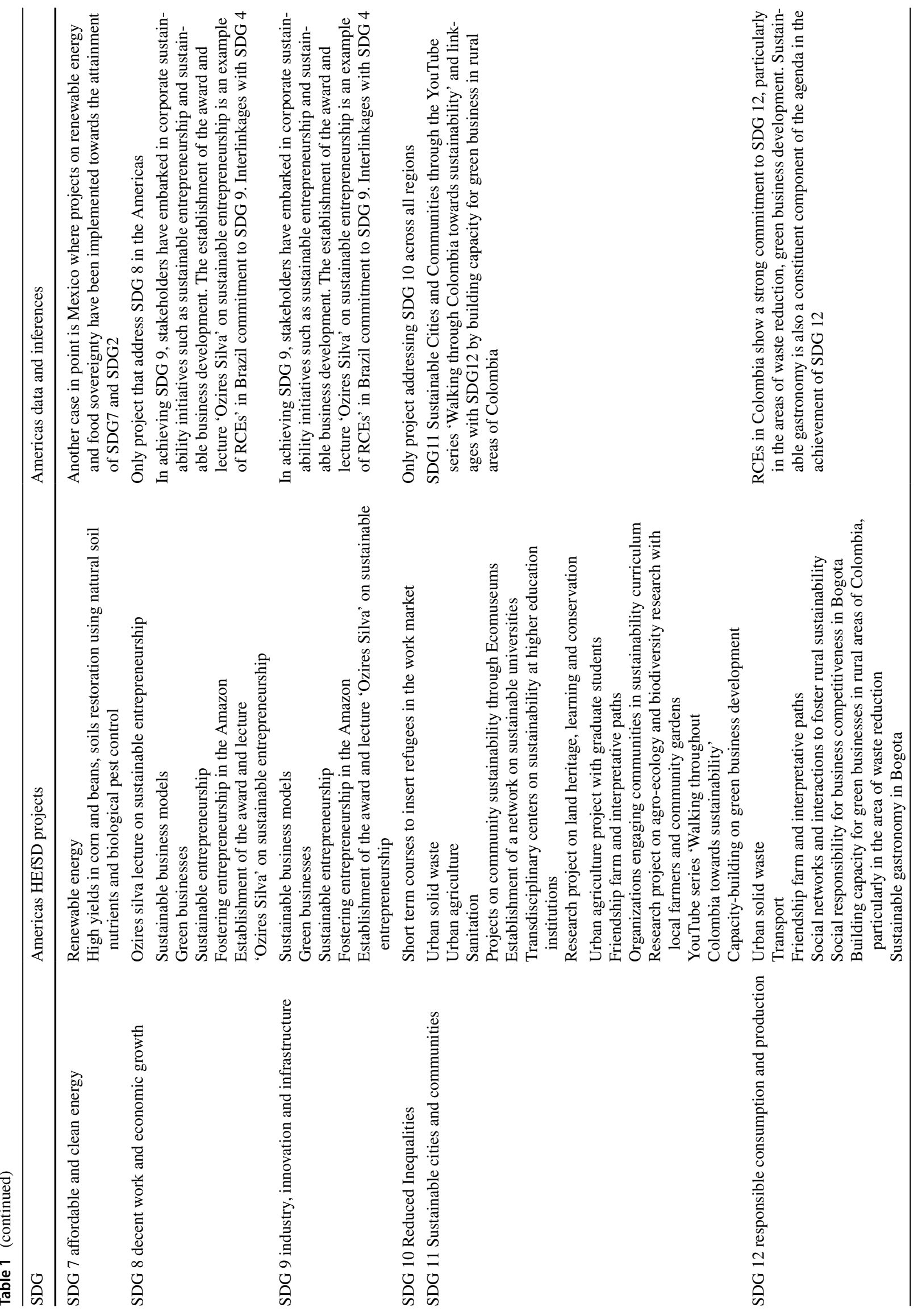




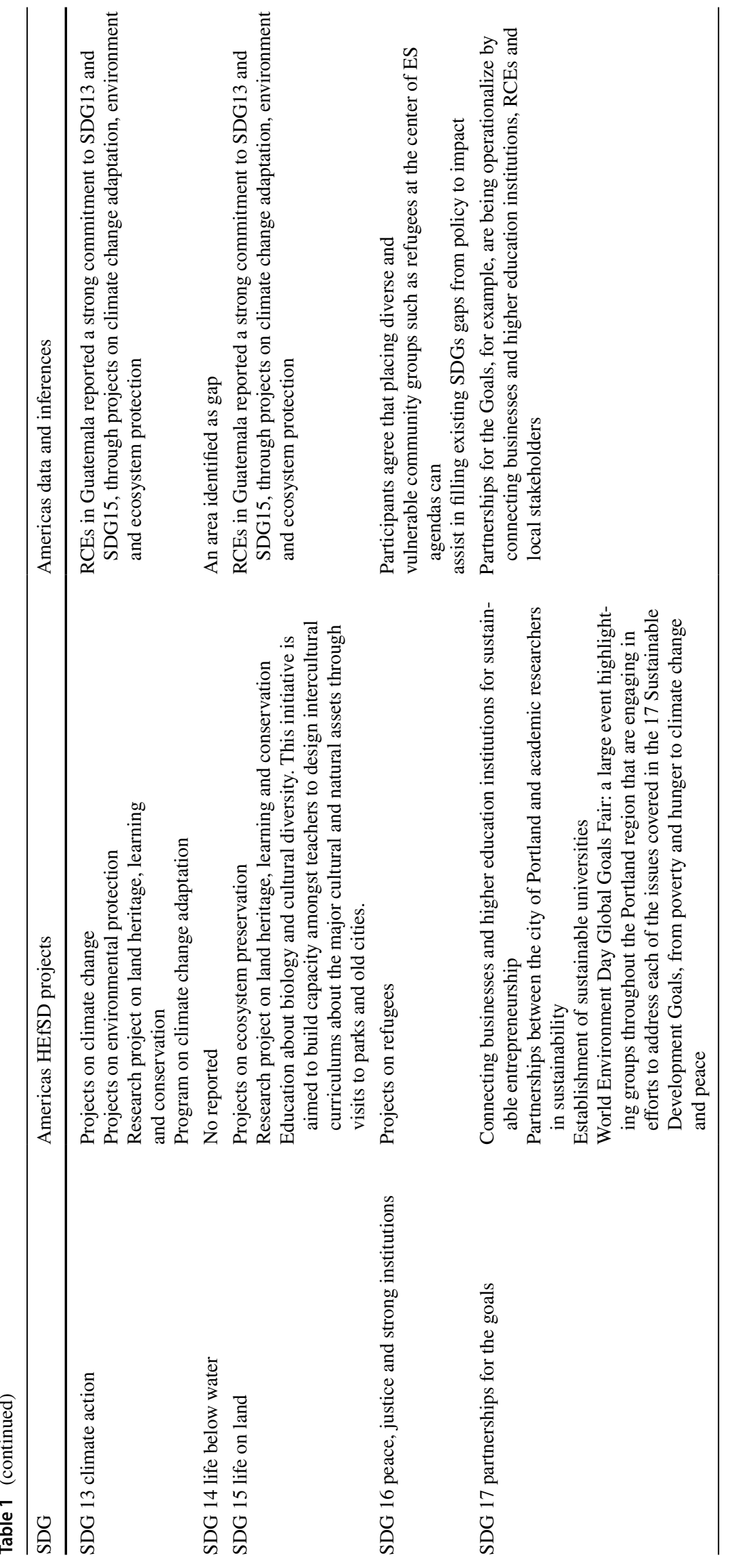




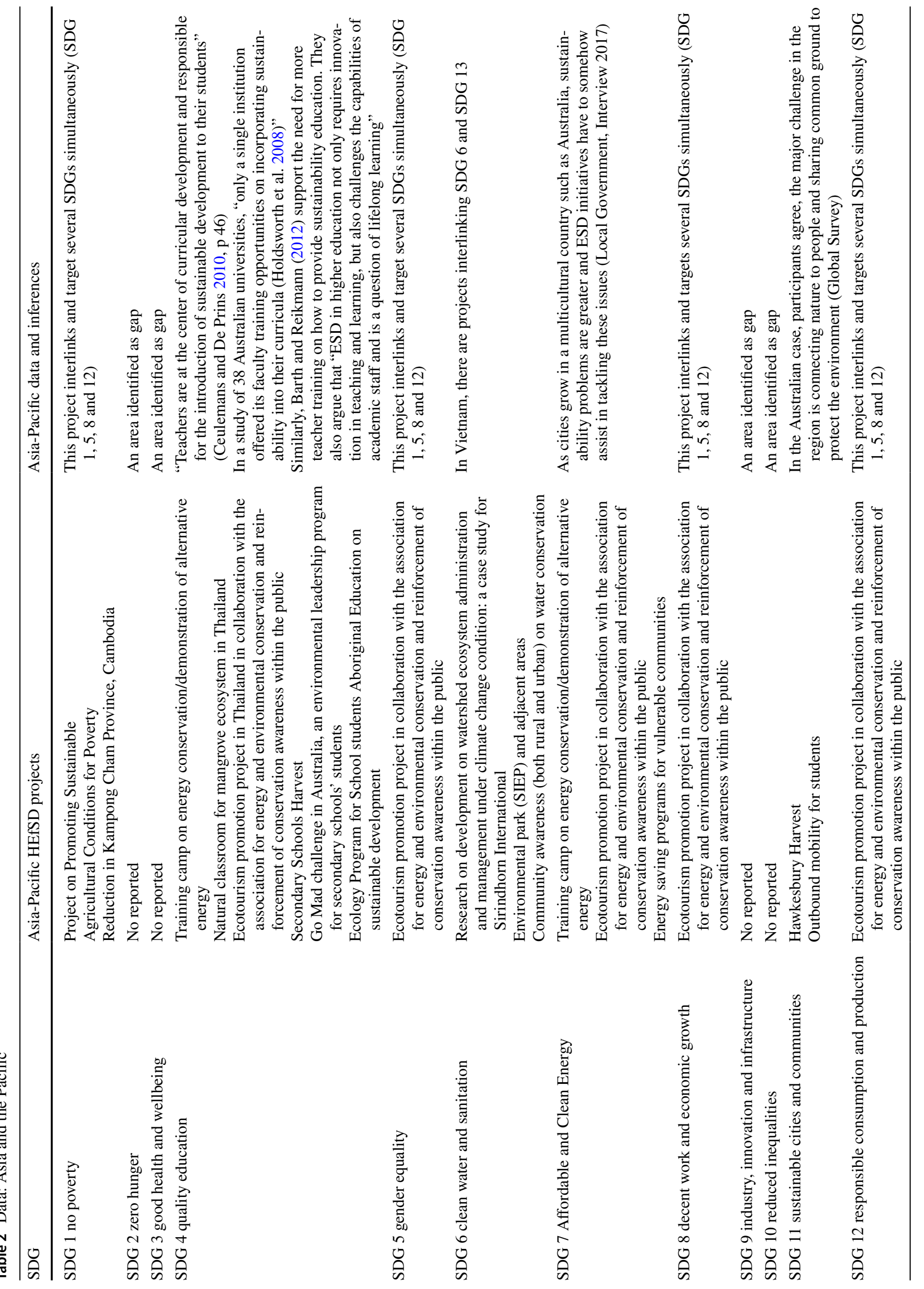




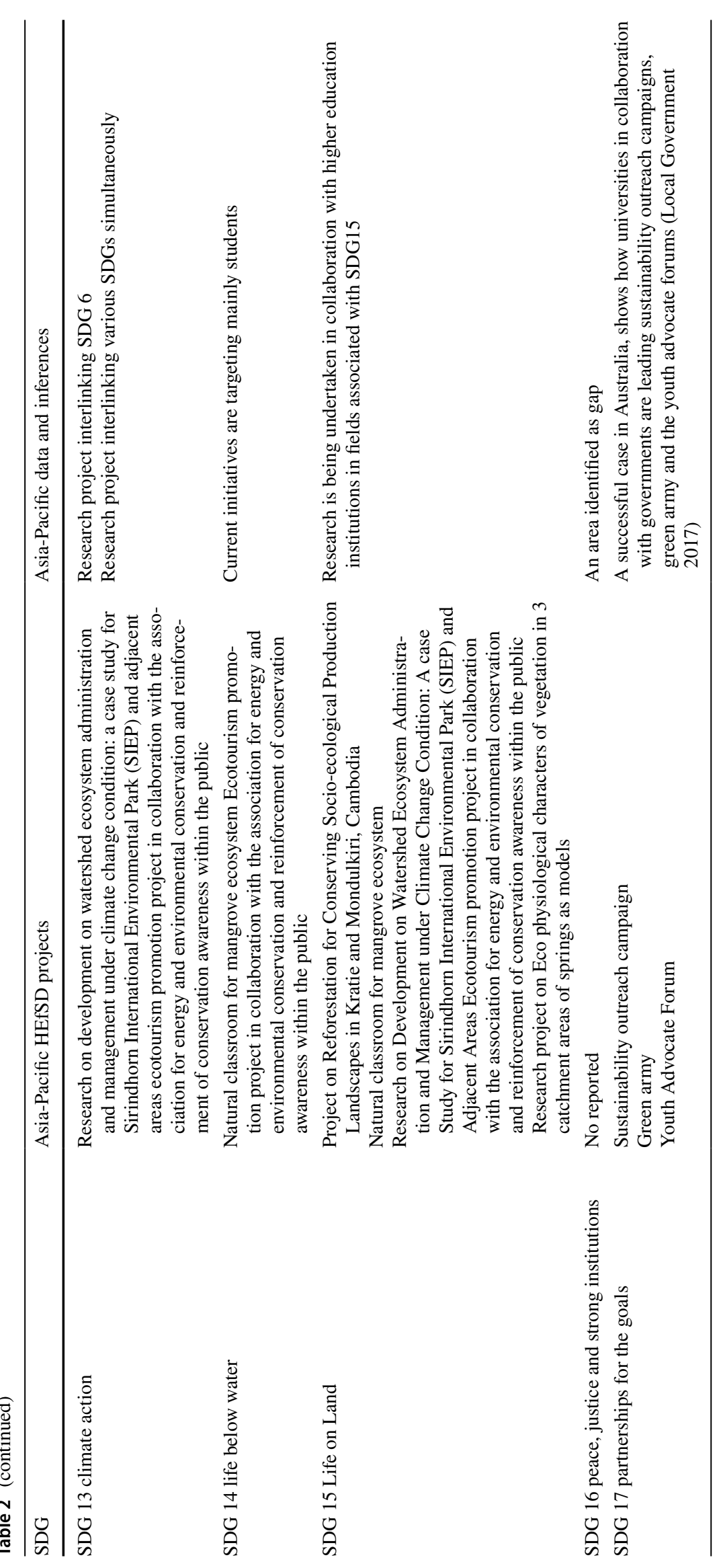




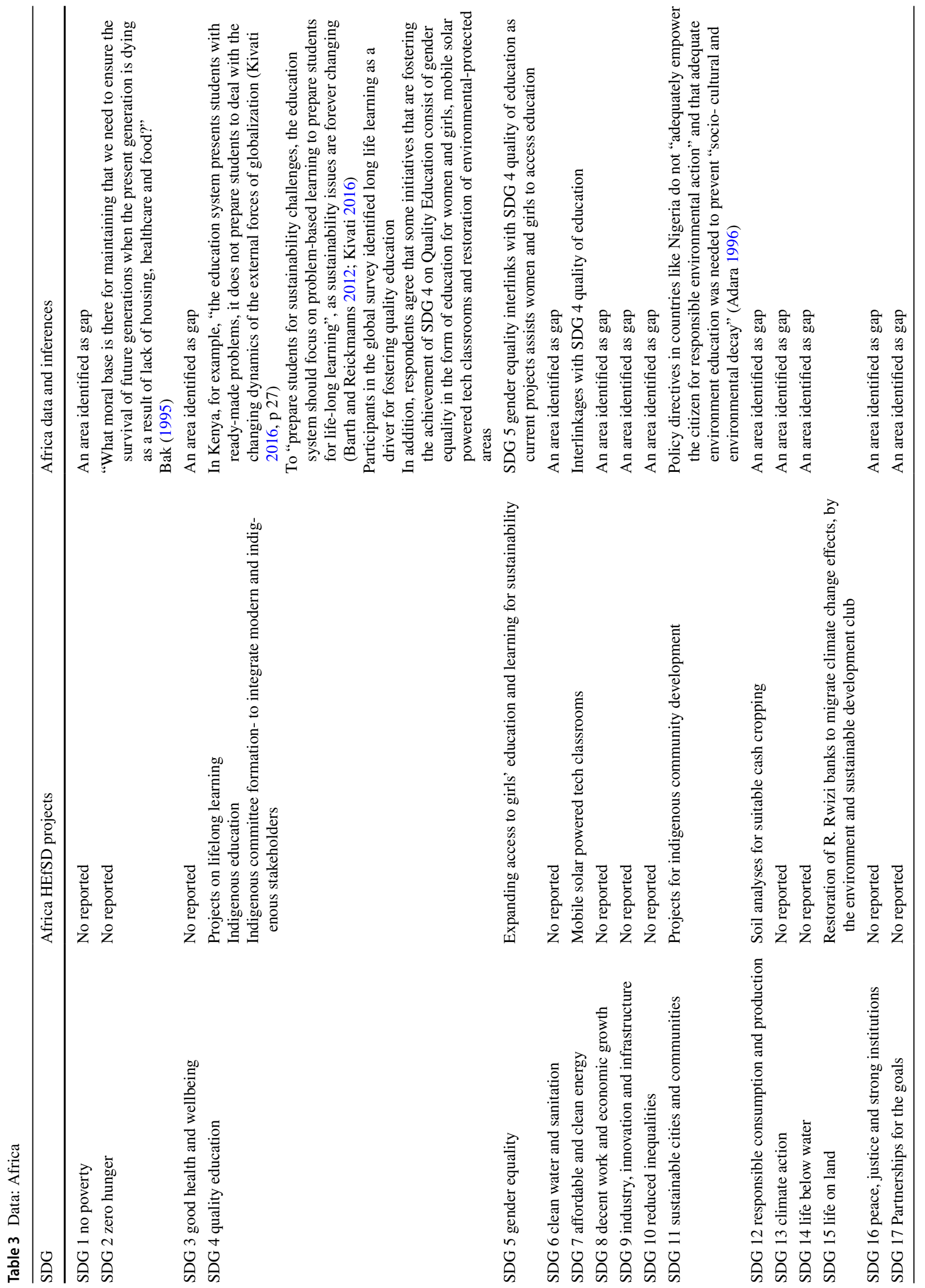


Table 4 Data: Europe

\begin{tabular}{ll}
\hline SDG & Europe HEfSD projects \\
\hline SDG 1 no poverty & No reported \\
SDG 2 zero hunger & No reported \\
SDG 3 good health and wellbeing & No reported \\
SDG 4 quality education & Introducing SD in the curricula for local train- \\
& ing actors \\
& Government funded project on Arts and SDGs. \\
& The project aims to enhance local interpreta- \\
& tion of SDG's in the Swedish context through \\
& art \\
Footprint of carbon of schools in Mediterra- \\
nean cities
\end{tabular}

Europe data and inferences

An area identified as gap

An area identified as gap

An area identified as gap

There is an increasing concern about the lack of ESD implementation as a field of study in higher education in Europe (Adomßent et al.,2014; Milutinović and Nikolić 2014)

The issue being that "education about sustainable development means teaching and learning about the concept itself, politics, policies and sustainable development theories" (Milutinovic and Nikolic 2014, p 108) Participants agree there is increasing interest but decreasing funding options (Global Survey)

It is also argued that the incorporation of ESD into Central Eastern Europe curricula is poorly documented, highlighting two cases from the Czech Republic and Bulgaria as two of a few examples of ESD in Eastern Europe. "One example depicts the evolution of teaching and supporting the sustainability paradigm in a devastated coal-mining area, the other relates to shifts in urban planning education in the course of societal changes in urban areas" (Adomßent et al. 2014)

Jóhannesson et al. (2011) suggest that the Icelandic approach to sustainability provides teachers and schools with more opportunities to deal with issues of sustainable development

Acknowledgement of the necessity of environmental education is centuries old as Froebel (1826) notes "The pupil will get the clearest insight into the character of things, of nature and surroundings, if he sees and studies them in their natural connection"

SDG 5 gender equality

SDG 6 clean water and sanitation

SDG 7 affordable and clean energy

SDG 8 decent work and economic growth SDG 9 industry, innovation and infrastructure SDG 10 reduced inequalities

SDG 11 Sustainable Cities and Communities

SDG 12 responsible consumption and production

SDG 13 climate action

SDG 14 Life Below Water

SDG 15 life on land

SDG 16 peace, justice and strong institutions
No reported

Removing pharmaceuticals from the waste stream

Capacity-building for sustainable technologies

Energy efficiency action plan for a municipality

No reported

Project on circular economy in Italy

No reported

Mapping ecosystem services in urban settings Urban agriculture

Workshops on sustainable cuisine in Portugal Project on social responsibility for innovation at Universidade Nova de Lisboa, Portugal

Project on Circular economy in Italy Fair production project in Germany

Projects on climate change leadership

Green storm water infrastructure through ecological design

Project on circular economy in Italy

Project on urban farming in Germany
An area identified as gap

Interlinkages with SDG 4 quality education

An area identified as gap

An area identified as gap

An area identified as gap

Interlinkages with SDG 17 and SDG 9

Interlinkages with SDGs 9, 12, 17

Interlinkages with SDG 11 
Table 4 (continued)

\begin{tabular}{lll}
\hline SDG & Europe HEfSD projects & Europe data and inferences \\
\hline SDG 17 partnerships for the goals & International network 'City Food' & \\
& Project on Circular economy in Italy & \\
\hline
\end{tabular}

specific findings in this regard are found in the section "Regional commonalities and differences".

The research team then analyzed these column entries for an overall narrative of a given region. Based on RCEs' stakeholders' perceptions, they then identified targeted areas and gaps for HEfSD in alignment with the SDGs in each region. The team then progressed the quotes into a story, which is presented in the narratives written in the following sections. Researchers took data and assessed whether RCE focal points and stakeholders thought the HEfSD approach was or was not relevant to given SDGs within their RCE and why this was the case. It was from this step of drawing theoretical interferences that important themes and perceived gaps of HEfSD in relation to the SDGs were found. These theoretical interferences then became the basis of Figs. 1, 2,
3 and 4. After obtaining results from four separate regions (Asia and the Pacific, Europe, Africa, and the Americas), a comparative analysis was undertaken to identify global commonalities and differences. Both perceived gaps and targeted areas in HEfSD were validated whenever possible with individual interviews and online survey results and presented at the end of the discussion and in the conclusion sections.

\section{Results and discussion}

Based on theory building as the governing methodological approach of this research, the analysis and results here presented were validated using various methodological techniques such as survey, literature review, interviews and
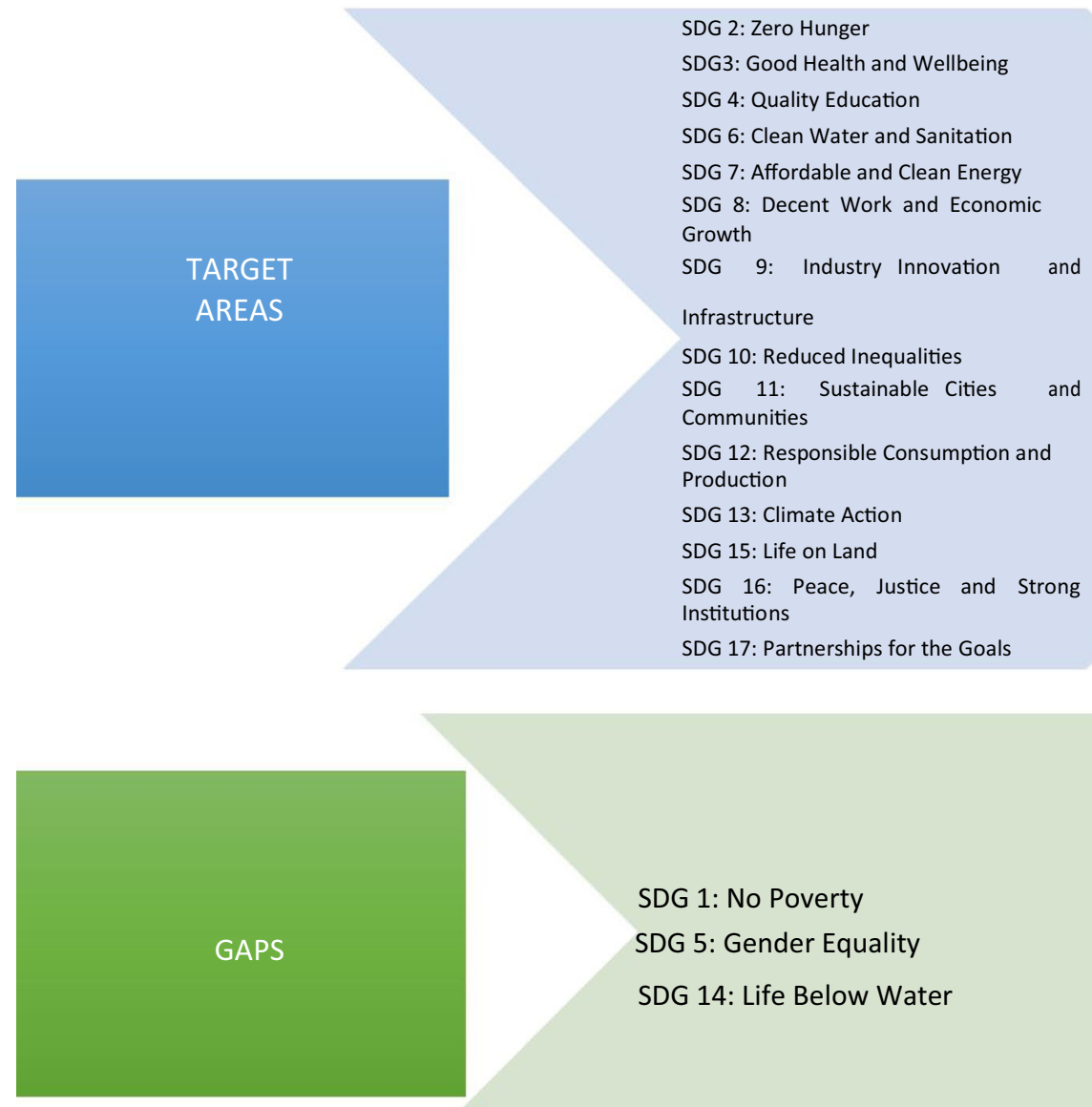

Fig. 1 ESD in the Americas: targeted areas and gaps 

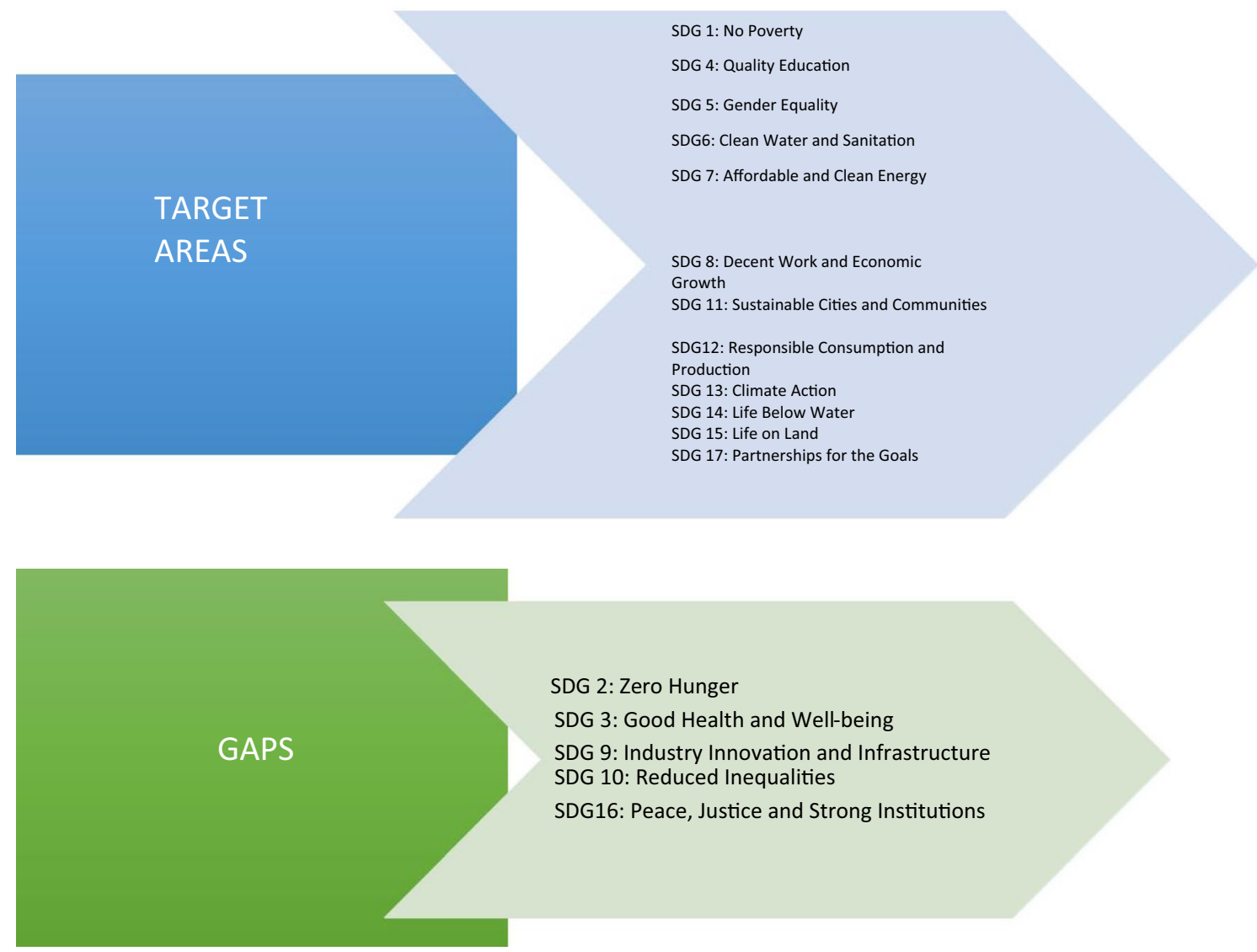

Fig. 2 ESD in the Asia and the Pacific: targeted areas and gaps

focus groups. The analysis begins reporting on findings in the Americas' case followed by research findings from Asia and the Pacific, Africa, and Europe. A section on regional commonalities and differences is also presented at the end of the discussion.

\section{HEfSD in the Americas: targeted areas and gaps}

Evidence indicates that participants from RCEs in the Americas are increasingly showing a stronger commitment to HEfSD policy, curriculum and practice in alignment with the Global Agenda for Sustainable Development. For instance, survey participants from an RCE based in North America state that "(they) have a large variety of groups, across sectors, that collaborate via many networks, including RCE Greater Portland. (They) have hosted a variety of different events and collaborated with multiple partners, to serve diverse audiences, across sectors, integrating the skills and resources of a variety of partners, with numbers exceeding our targets". However, issues on existing collaborative processes for HEfSD remain. With only three of the SDGs perceived as gaps in HEfSD by RCEs in the Americas, namely SDGs 1, 5 and 14 (Fig. 1), respondents reported that more involvement of educators and students from higher education institutions in collaborative processes was perceived as a priority to advance towards HEfSD: 'We continue to grow, with new programs and events, in addition to more volunteers, interns, and fellows, which all require coordination and management. It is not enough to depend on volunteers to meet our capacity needs. This led to inequity in workloads and burn out of our outgoing Director. The network has struggled due to the leaders being stretched too thin. We need funding to expand staff capacity'-research participants' state. In addition, results indicate that social sustainability issues in the achievement of SDGs are not as proactively targeted as environmental sustainability matters.

Within the Americas, RCEs and stakeholders are embracing a collaborative approach to operationalize HEfSD. Nevertheless, participants' perceptions show that stronger involvement of students and teachers from higher education requires greater attention. A major issue reported both in theory and practice in the achievement of SDG 4, for instance, concerns students' involvement and lack of understanding and practice of 'overall sustainability' (Comm and Mathaisel 2008; Barth and Reickmann 2012) (Table 1, Column 2, Row 5). Lack of research on sustainability uptake in 

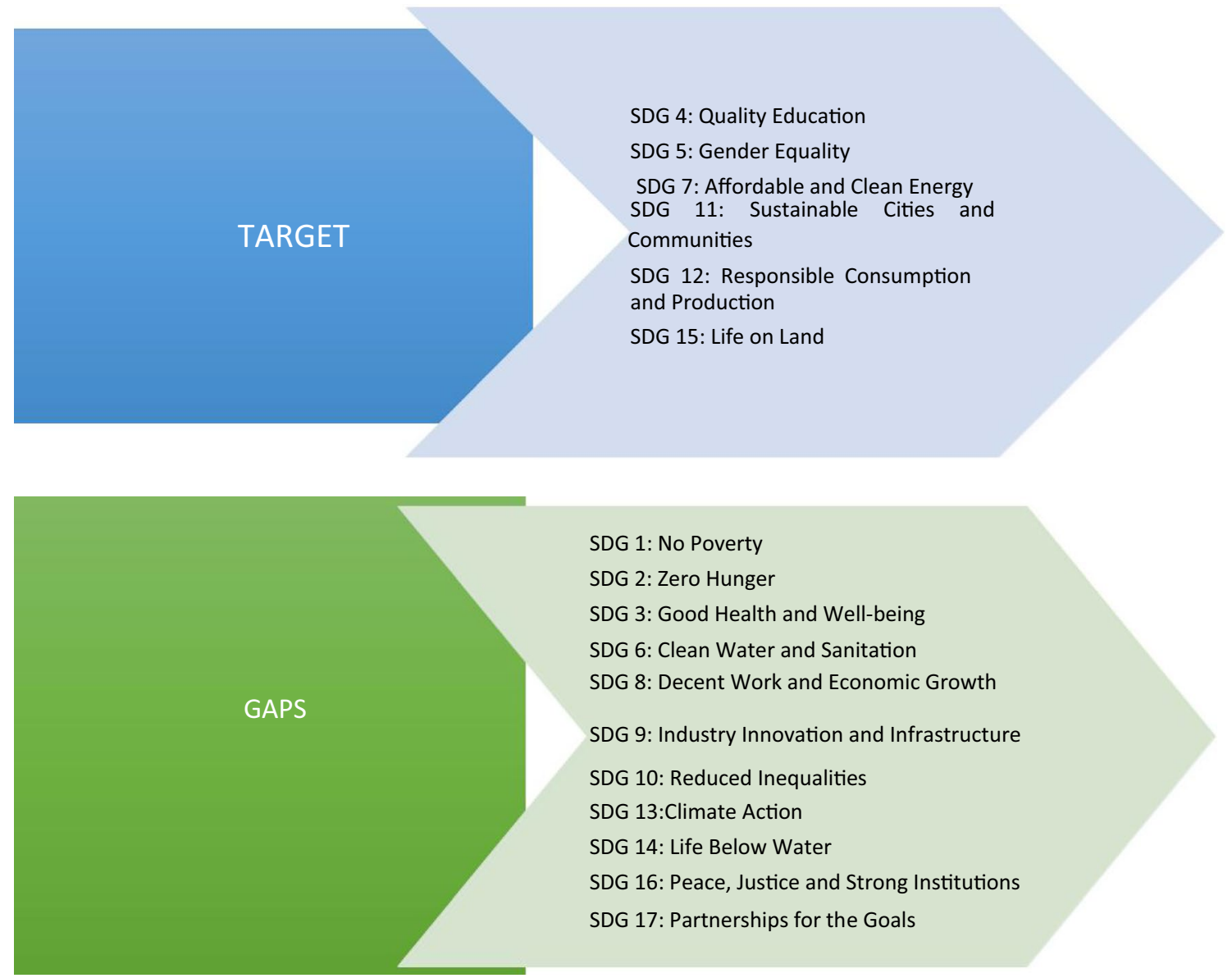

Fig. 3 HEfSD in Africa: targeted areas and gaps

broader disciplines, limited training designed to facilitate sustainability integration into their curricula and scarce content or time for HEfSD are major barriers faced by teachers and students (Puk and Behm 2003). To address this issue, in North America, for instance, RCE Greater Portland is working with eco-psychologists to create workshops to train students to learn about resilience in the face of challenging sustainability issues, such as climate change and environmental injustice. This project interlinks and targets SDGs 4 and 17 and has led to ongoing collaboration between researchers and stakeholders in the City of Portland in North America (Table 1, Column 2, Row, 5).

Whilst in North America, the achievement of SDGs such as SDG 4 has a strong focus on students, participants in South America argue that major attention needs to be paid to educators in higher education. Hernandez et al. (2018) concluded that dissemination and implementation of international HEfSD frameworks in Latin America have been slow and sporadic. Although there are some signs to implement HEfSD into curricula in Brazil and Colombia, these practices have not been substantial or have not permeated higher Education institutions' sustainable development strategies per se. A Brazilian RCE is tackling this issue by interlinking SDGs 4, 8 and 9 through the establishment of the 'Ozires Silva' lecture and award on sustainable entrepreneurship (Table 1, Column 2, Rows 5, 9 and 10). Successful cases have also been documented in the literature by Barth and Reickmann (2012) who reported the outcomes of a sustainability training program for educators in Ecuador. Findings show that first it provided academics with a broader understanding of sustainability issues. Second, teaching routines and professional performance were transformed, encouraging a more participatory and active approach from educators in higher education (Table 1, Column 2, Row 5).

Another major finding for HEfSD in the Americas concerns social sustainability issues, which according to participants have been overlooked when compared to environmental sustainability matters, a situation that they believe is compromising the attainment of SDGs 1 and 5 (Table 1, Column 2, Rows 2 and 6). Participants agree that placing diverse and vulnerable community groups such as indigenous communities and refugees at the center of HEfSD agendas can assist in addressing this issue and can also show a strong commitment to SDG 16 (Table 1, Column 

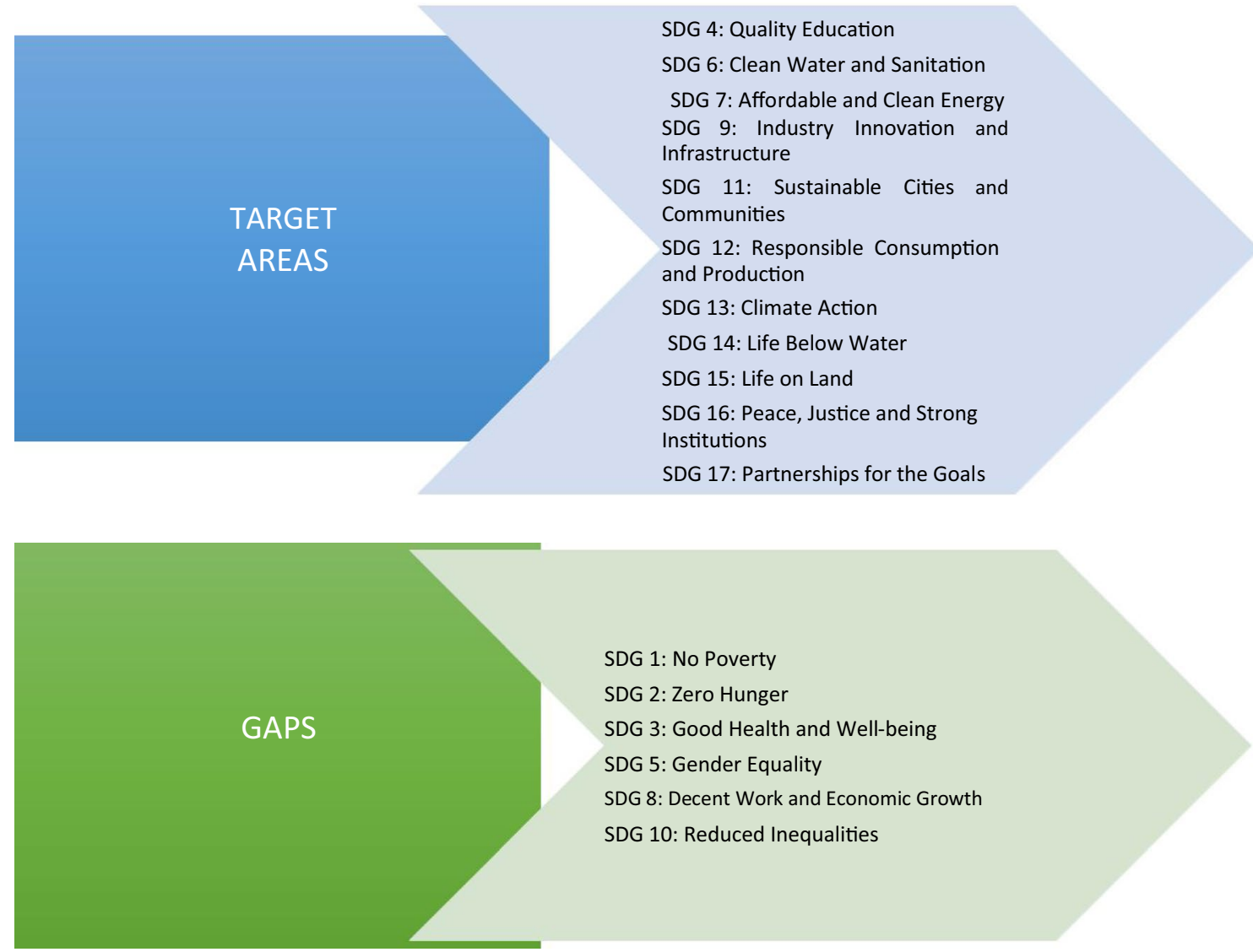

Fig. 4 HEfSD in Europe: targeted areas and gaps

2, Row 17). There is an increasing consensus that pressing social sustainability issues, such as the arrival of disruptive industries (e.g., extractives), climate change, community displacement from rural contexts to urban and periurban areas and increased conflict over land ownership are factors that are threatening vulnerable community groups (Franco, 2014). This issue is being addressed in HEfSD from various locations throughout the Americas. For example, a Canadian RCE is targeting SDG 3 through a project aimed to strengthening human-animal relationships as a doorway to indigenous wellness (Table 1, Column 2, Row 4).

Interestingly, in South America, a capacity-building project for refugees to access the labour market, led by a Brazilian RCE is the only initiative across all RCEs surveyed in the Americas in relation to the attainment of SDG 10 within HEfSD (Table 1, Column 2, Row 11). Other efforts that represent a potential to achieve social sustainability within HEfSD are being conducted in Colombia. For instance, SDG 11 is targeted through the educational YouTube series 'Walking through Colombia towards sustainability' (Table 1, Column 2, Row 12) - an initiative developed by the university that explores connections between the environment and groups in vulnerable conditions. Major attention is also being paid to SDG 12 through projects on rural community capacity building through green business development and sustainable gastronomy (Table 1, Column 2, Row 13).

Results also show there is a plethora of environmental sustainability initiatives for HEfSD in the Americas. A Brazilian RCE, for example, reported the creation of the 'Instituto de Ciência e Tecnologia de Estações de Tratamento de Esgoto Sustentável' (Institute of Science and Technology for Sustainable Sewage Treatment) in alignment with SDG 6 (Table 1, Column 2, Row 7). Another case in point is and RCE in Mexico where projects on renewable energy and food sovereignty have been implemented towards the attainment of SDG 7 (Table 1, Column 2, Rows 8). In addition, a Guatemala-based RCE shows a strong commitment to SDGs 13 and 15, through projects on climate change adaptation, environment and ecosystem protection, respectively (Table 1, Column 2, Rows 14 and 16).

The current targeted environmental areas (Fig. 1) champion the rhetoric on misconceptions of global policy and how they are jeopardizing HEfSD practice. Barraza et al. (2003) argue that the element of North-South politics or the notion that "globally agreed is hampering HEfSD and that environmental education perspectives could be seen as 
providing the 'North' with yet another means to re-shape and re-define people's behaviors and thinking in the 'South', in what Escobar (1995) sees can become a subtle but effective control mechanism, and another expression of neo-colonialism". In some cases, governments follow this statement and ministries of education have given relatively low priority to what they perceive (or better, misperceive) as a 'fashionable trend' (Dlouhá and Moldan 2013). This issue deserves closer attention within the region, as it can compromise the advancement of HEfSD in policy, curriculum and practice.

\section{HEfSD in Asia and the Pacific: targeted areas and gaps}

Results indicate that environmental sustainability is also a key component in the HEfSD agenda in Asia and the Pacific. However, there is scarce attention on initiatives that address sustainability policy issues, such as governance and peace security, as well as social sustainability matters. Although higher education institutions in the region exist in a context where sustainable development policy is actively backed by strong government policies in nations such as Australia, China, Japan and the Philippines (Ryan et al. 2010), only two projects reported from RCEs in the region relate to the attainment of policy sustainability matters. An Australianbased RCE in collaboration with the local government reported the projects 'Green Army' and the 'Youth Advocate Forum' as two successful cases in the achievement of SDG 17 (Table 2, Column 2, Row 18). SDG 16 remains a gap that deserves nuanced attention, as no projects in relation to this Goal have been reported by participant RCEs (Table 2, Column 2, Row 18).

Research findings also show the major issues in further addressing social sustainability within HEfSD in relation to the attainment of SDG 4, particularly in regard to lack of educators' capacity to teach sustainability. Similarly, as cities grow, more attention is needed to vulnerable communities and indigenous groups in multicultural settings. Little regard for these issues was perceived in a review of HEfSD initiatives for the region. Other gaps identified in the HEfSD agenda are as follows: SDGs 2, 3, 9, 10 and 16 (see Fig. 2). Targeted areas are also shown in Fig. 2 and are discussed below. Targeted areas those where there are existing projects while gaps indicate an absence of them.

Results show that environmental sustainability issues have been tackled through SDG interlinkages within HEfSD in the region. A case in point is an initiative for students on a 'natural classroom' to learn about mangrove ecosystems in South East Asia, linked to SDGs 4 and 14 (Table 2, column 2, Row 15), whilst in Vietnam, a research project on 'Watershed Ecosystem Administration under Climate Change Condition' interlinks SDGs 6 and 13 simultaneously (Table 2, Column 2, Rows 7 and 14). Scholars have also documented interlinkages in the academic literature between SDG 13 and SDG 5, particularly in the case of Bangladesh. CorcoranNantes and Roy (2018), for instance, explore the genderspecific implications of climate change. The authors argue that although climate change impacts globally, its effects are not equal everywhere due to race and gender inequality, amongst other factors.

Interlinkages between SDGs were also found in HEfSD in Thailand. For example, a project for ecotourism within a Thai RCE currently targets SDGs 1, 5, 8, and 12 (Table 2, Column 2, Rows 6, 9 and 13). Findings show that in Bangladesh, efforts have been undertaken to forge sustainable livelihoods and achieve SDG 8. For instance, Sultana and Thompson (2007) documented the case of fisheries as a way to empower communities, access resources and foster overall sustainability. Evidence also shows that in Southeast Asian countries actions are taken towards the achievement of SDG 12 within HEfSD, particularly in relation to waste treatment and sustainable waste management (Ngoc and Schnitzer 2009). Similarly, two projects in Australia, one on 'Outbound Mobility for Students' and the 'Hawkesbury Harvest for Sustainable Natural Resource Development' are also being carried out to target SDG 11 (Table 2, Column 2, Row 12). According to participants' perceptions, environment is a key area, as the major challenge in the region is connecting nature to people and sharing common ground to protect the environment. However, evidence shows that areas that need more attention are those related to the social sustainability (see Fig. 2).

Special attention needs to be paid to social sustainability matters for HEfSD in the region. For instance, in the achievement of SDG 4, there are ongoing issues on teacher training and preparation of the youth to face sustainability challenges is compromising the attainment of SDG 4. "Teachers are at the center of curricular development and responsible for the introduction of sustainable development to their students" (Ceulemans and De Prins 2010, p 46). In a study of 38 Australian universities, only a single institution offered its faculty training opportunities on incorporating sustainability into their curricula (Holdsworth et al. 2008). Participants agree there is a need for more teacher training on how to teach sustainability, an issue that had also been documented by Barth and Reikmann (2012, p 29). They argued that HEfSD "not only requires innovation in teaching and learning, but also challenges the capabilities of academic staff and is a question of lifelong learning".

Another issue derived from the existing social sustainability gap concerns increasing vulnerability of various communities. As cities grow, sustainability problems within them will become greater, and any HEfSD initiatives addressing them will be required to become more inclusive. An Australia-based RCE, for example, is using HEfSD to conduct educational programs on energy saving in vulnerable and 
multicultural communities-an initiative that targets SDG 7 (Table 2, Column 2, Row 8). This inclusive approach to HEfSD is helping students in higher education institutions learn more about vulnerable communities, particularly multicultural and indigenous community groups. With a focus on vulnerable communities, educators and students, key actors are required to foster connections between social and environmental sustainability matters in a more inclusive and holistic manner.

\section{HEfSD in Africa: target areas and gaps}

Current trends on HEfSD in Africa have strongly been criticized. "What moral base is there... to ensure the survival of future generations when the present generation is dying as a result of lack of housing, healthcare and food?" (Bak 1995). According to Okolie (2003, p 1) "higher education in Africa should be rethought and restructured to better reflect the actual lived experiences of the vast majority of Africans". The author proposes that this can be done by creat[ing] spaces for the expropriation of what is suitable in modern science and technology and their rearticulation with elements of Africa's traditions, values, practices and relationship with nature to pursue development policies that are African-centered and more sustainable.

It is claimed that sustainability policy in African countries like Nigeria do not empower the citizen for responsible environmental action and that environmental education was needed to prevent "socio-cultural and environmental decay (Adara 1996). This issue is reflected in research findings showing that eleven (11) out of the seventeen (17) SDGs are not being widely covered as shown in Fig. 3. Participants agree in their perception that this is due to a lack of a governing approach to tackle pressing sustainability issues. Instead, there are a number of scattered initiatives aligned with various SDGs. Participants also stated that this is also due mainly to lack of capacity amongst stakeholders to develop an integrated approach to HEfSD across the region. In addition, findings indicate there is increasing interest in tackling social sustainability issues through SDGs interlinkages and a particular focus on vulnerable community groups, such as indigenous peoples. Likewise, evidence shows that environmental sustainability issues remain partially covered and several SDGs still need to be addressed, as follows: SDGs 1, 2, 3, 6, 8, 9, 10, 13, 14, 16, and 17 (See Fig. 3). Targeted areas are also shown in Fig. 3 and are discussed below.

Findings show there is a major focus on vulnerable community groups and the exploration of SDG interlinkages to achieve social sustainability. Such interest is reflected, for example, in HEfSD in the region focusing on the attainment of SDG 4. Evidence shows strong interlinkages between SDG 4 and other SDGs with a major focus on community groups and lifelong learning. It is argued that HEfSD should prepare students for sustainability challenges by focusing on problem-based learning to prepare students for life-long learning and face forever changing sustainability issues (Barth and Reickmann 2012; Kivati 2016). At the present time "the education system presents students with readymade problems, it does not prepare them to deal with the changing dynamics of the external forces of globalization" (Kivati 2016, p 27). Findings show that active projects interlinking SDG 4 and SDG 11 are focused on community empowerment to prepare future generations to face just these types of sustainability challenges. A case in point is a Nigerian-based RCE that is currently targeting SDG 11 through indigenous community capacity development (Table 3, Column 2, Row, 12). Strong interlinkages between SDGs 4, 5 and 7 were also found in review of a number of RCE projects on HEfSD in the region. A program to increase women's and girls' access to education through mobile solar powered tech classrooms is one such connection (Table 3, Column 2, Rows 5, 6 and 8).

Whilst nuanced attention is being paid to social sustainability in this region, scarce attention has been devoted to the achievement of environmental issues with the exception of a few isolated projects. For example, a Nigerian RCE is working on a HEfSD project on 'soil analyses for suitable cash cropping' that aims to address SDG 12 (Table 3, Column 2, Row 13). Another case in point is a Uganda-based RCE where the 'Environment and Sustainable Development Club' targets both SDGs 13 and 15 through HEfSD by leading the restoration of the Rwizi Banks to mitigate climate change effects (Table 3, Column 2, Row 16). Despite current attempts to contribute to the achievement of SDGs, work needs to be done to cover the eleven (11) SDGs that remain unaddressed from reported projects at this time (see Fig. 3).

\section{HEfSD in Europe: targeted areas and gaps}

External governance factors have impacted HEfSD in Europe. This issue is reflected in current HEfSD gaps, namely SDGs 1, 2, 3, 5, 8, and 10 (See Fig. 4). Targeted areas are also shown in Fig. 4 and discussed below. Decreasing funding options, 'dynamically flat' stakeholder engagement and low accountability are some of the factors that hamper HEfSD policy, curriculum and practice in the region. Innovation as a driver for HEfSD and emphasis on urban sustainability have also been found to be key themes in the European HEfSD agenda.

The notion of HEfSD in the European case has been widely discussed and criticized. It is argued that "education about sustainable development means teaching and learning about the concept itself, politics, policies and sustainable development theories" (Milutinović and Nikolić (2014, p 108). Few practical HEfSD applications have been documented in the academic literature, with only a 
few cases reported in Europe. One example in the Czech Republic depicts the evolution of teaching and supporting the sustainability paradigm in a devastated coal-mining area. A Bulgarian case relates to shifts in urban planning education within HEfSD in the course of societal changes in urban areas (Adomßent et al., 2014). Similarly, an examination of a Portuguese case shows how sustainability principles in education have been integrated successfully making use of technology and online strategies (Azeiteiro et al. 2015). Another case in point shows that government organizations across Europe have taken actions to integrate sustainability principles into the curriculum, including within higher education (Sleurs 2008; Mochizuki and Fadeeva 2010). The abovementioned cases show practical applications of how higher education institutions' commit to move from sustainability theory to impact.

Research findings also show that innovation has become a driver for the attainment of SDGs in HEfSD within Europe. In Sweden, for example, current initiatives to achieve SDG 4 include 'sustainable development integration in the curricula', programs to 'increase awareness of SDGs through the use of art' and projects on the 'footprint of carbon of schools in Mediterranean cities' (Table 4, Column 2, Row 5). Innovation as a driver for HEfSD has been documented in an Icelandic case where teachers and schools are given the opportunity to innovate to deal with sustainable development issues (Jóhannesson et al. 2011). Innovative approaches to environmental education are centuries old as Froebel (1826) notes "The pupil will get the clearest insight into the character of things, of nature and surroundings, if he sees and studies them in their natural connection". At the present time, innovative education programs in the form of capacity building are undertaken to achieve SDG 6 implementation, such as a 'capacity-building project for sustainable technologies and pharmaceuticals removal from the waste streams' (Table 4, Column, 2, Row, 7).

Evidence also shows there is a particular interest in exploring interlinkages to tackle urban sustainability as such within European HEfSD. A Germany-based RCE reported projects on 'mapping ecosystem services in urban settings' and 'urban farming' to target simultaneously SDGs 11 and 16 (Table 4, Column 2, Rows 12 and 17). Another case in point was reported by an Albanian RCE currently working in collaboration with the local government to develop 'energy efficiency action plans' at the municipality level. This initiative targets both SDGs 17 and 7 (Table 4, Column 2, Rows 8 and 18). In addition, an Italian RCE is conducting a project on the 'circular economy' that interlinks SDGs 9, 12, 15, and 17 simultaneously (Table 4, Column 2, Rows 10 , 13, 16 and 18). Although findings show RCEs have been proactive in translating HEfSD into practice in the region with close alignment to the Global Agenda for Sustainable
Development, six (6) SDGs remain unaddressed in HEfSD from RCEs surveyed in this research.

\section{Regional commonalities and differences}

Even with the release of the Brundtland report in 1987 and the issuance of the Global Agenda for Sustainable Development by the United Nations in 2015, there is still room for improvement to action the global goals in HEfSD to move forward with relevant policy, curriculum and practice. Evidence from this research examining RCEs working with HEfSD indicates that five (5) SDGs are widely targeted in higher education across all regions, namely SDGs 4, 711,12 and 15 (see Table 5). Findings also show that major gaps remain in the attainment of SDGs 1, 2, 3 and 10. Interestingly, SDG 10 is being paid limited attention across all regions with only one project on 'capacity-building for refugees' reported in the Americas (Table 1, Column 2, Row 11). Findings also indicate that more attention needs to be devoted to HEfSD in the African region where eleven (11) SDGs were perceived as gaps in HEfSD among the RCEs surveyed. This is opposed to the Americas where only three (3) of the SDGs were perceived as gaps in HEfSD by RCEs.

Participants agree that current challenges and opportunities in practicing HEfSD in alignment with the Global Agenda for Sustainable Development comprise several factors, with limited understanding of regional-based differences being one of the most critical. Regional disparities and similarities cannot be overlooked and need to be further explored. Neglecting regional differences may hamper HEfSD and stakeholders' ability to comparably and successfully action the Global Agenda for Sustainable Development. A case in point is SDG 13, perceived as a priority for HEfSD in the Americas, Asia and the Pacific, and Europe. Yet, it is perceived as a gap for HEfSD in Africa (See Table 5, Column 4, Row 14). Lessons can be learned across regions and in doing so, enhanced collaboration is required across geographical locations, as well as the RCEs, higher education institutions and key stakeholders within them.

\section{Research limitations}

A further exploration of regional commonalities and differences was compromised due to existing research limitations. A methodological limitation encountered, however, was the lack of the literature in the field in languages other than English. Yet, researchers surveyed RCE focal points from Spanish- and Portuguese-speaking countries and translated research findings wherever possible. As this is a global study, questions remain regarding scholars' perceptions in non-English-speaking countries, particularly those coming from the Global South. This issue had already been risen by Aikens et al. (2016, p 335) who argue that in "their attempts 
Table 5 HEfSD: regional targeted areas and gaps

\begin{tabular}{|c|c|c|c|c|}
\hline SDG & Americas & Asia-Pacific & Africa & Europe \\
\hline $\begin{array}{c}\text { SDG 1 } \\
\text { No Poverty }\end{array}$ & & - & & \\
\hline $\begin{array}{c}\text { SDG 2 } \\
\text { Zero Hunger }\end{array}$ & - & & & \\
\hline $\begin{array}{c}\text { SDG } 3 \\
\text { Good Health and } \\
\text { Wellbeing }\end{array}$ & - & & & \\
\hline $\begin{array}{c}\text { SDG } 4 \\
\text { Quality Education }\end{array}$ & - & - & - & - \\
\hline $\begin{array}{c}\text { SDG 5 } \\
\text { Gender Equality }\end{array}$ & & - & - & \\
\hline $\begin{array}{c}\text { SDG } 6 \\
\text { Clean Water and } \\
\text { Sanitation }\end{array}$ & - & - & & - \\
\hline $\begin{array}{c}\text { SDG } 7 \\
\text { Affordable and Clean } \\
\text { Energy }\end{array}$ & - & - & - & - \\
\hline $\begin{array}{c}\text { SDG } 8 \\
\text { Decent Work and } \\
\text { Economic Growth }\end{array}$ & - & - & & \\
\hline $\begin{array}{c}\text { SDG 9 } \\
\text { Industry, Innovation } \\
\text { and Infrastructure }\end{array}$ & - & & & - \\
\hline $\begin{array}{c}\text { SDG 10 } \\
\text { Reduced Inequalities }\end{array}$ & - & & & \\
\hline $\begin{array}{c}\text { SDG 11 } \\
\text { Sustainable Cities } \\
\text { and Communities }\end{array}$ & - & - & - & - \\
\hline $\begin{array}{c}\text { SDG } 12 \\
\text { Responsible } \\
\text { Consumption and } \\
\text { Production }\end{array}$ & - & - & - & - \\
\hline $\begin{array}{c}\text { SDG 13 } \\
\text { Climate Action }\end{array}$ & - & - & & - \\
\hline $\begin{array}{c}\text { SDG 14 } \\
\text { Life Below Water }\end{array}$ & & - & & - \\
\hline $\begin{array}{c}\text { SDG } 15 \\
\text { Life on Land }\end{array}$ & - & - & - & - \\
\hline $\begin{array}{c}\text { SDG } 16 \\
\text { Peace, Justice and } \\
\text { Strong Institutions }\end{array}$ & - & & & - \\
\hline $\begin{array}{c}\text { SDG } 17 \\
\text { Partnerships for the } \\
\text { Goals }\end{array}$ & - & - & & - \\
\hline
\end{tabular}


to provide a comprehensive survey of the policy literature to date, (they) recognize the limits of surveying only English language literature". Nevertheless, a vast majority of the HEfSD literature came from English-speaking countries, with few studies from Latin America, Asia, and non-anglophone Europe. For some scholars this is due to the fact that some international organizations "only valued and, therefore gave voice to, the experiences and perspectives of representatives from developed countries" (González-Gaudiano 2006). This is a limitation that needs nuanced attention in further studies.

Another research limitation has to do with scared data to investigate economic aspects of sustainable development. Findings show that social and environmental factors are perceived by participants as more relevant and limited attention has been placed on the economic arena. This is an issue that requires major attention.

\section{Conclusions}

Evidently, increasing sustainability challenges have resulted in difficulties to action global goals in HEfSD, most of which call for a complete overhaul of the university system. In doing so, this research suggests closer attention to essential factors to advance HEfSD, policy, curriculum and practice are essential, as follows: governance aspects of HEfSD, a governing approach to HEfSD and Social and Environmental Interlinkages in HEfSD.

\section{Governance aspects of HEfSD}

A major finding derived from this study shows that a more effective collaborative governance approach within higher education for HEfSD is essential. As sustainability issues exacerbate and become more interconnected, collaboration becomes not only more essential but also more challenging. Findings show that major issues in collaborative processes include but are not limited to lack of involvement of key stakeholders such as educators and students, a lack of communication amongst stakeholders, low accountability, scarce funding opportunities, and limited stakeholders' capacity to successfully operationalize HEfSD. These are issues that require closer attention and further research.

\section{Governing approach to HEfSD}

Another major finding has to do with the governing approach and thematic focus on HEfSD. There is a focus on environmental sustainability, in the Americas, Asia and the Pacific and Europe. Yet, dissimilar results were found in Africa where social sustainability matters are perceived as major priorities within higher education institutions. In addition, evidence from the African case shows the lack of a governing approach to HEfSD which has resulted in a plethora of scattered activities. However, this should be perceived as an opportunity to further explore how SDGs can be effectively integrated as a governing approach to HEfSD in policy, curriculum and practice. Further exploration on interlinkages amongst SDGs in HEfSD and rigorous investigation on existing gap areas and factors preventing the attainment of those are opportunities for further research.

\section{Social and environmental interlinkages}

Stronger interlinkages between social and environmental matters are needed to fill existing social sustainability gaps in HEfSD. For example, in the Americas and AsiaPacific, a lack of interconnectedness between these two areas is hampering the attainment of SDG 10. Closer attention should be paid to vulnerable community groups, particularly indigenous peoples when exploring socio-environmental interlinkages.

Overall it is important that findings here presented and recommendations for research are taken seriously to action the Global Agenda for Sustainable Development in HEfSD. This will not only contribute to build knowledge on current scholarly debates on HEfSD but may also assist higher education institutions and their stakeholders in moving forward towards more relevant HEfSD policy, curriculum and practice.

Linkages with economic aspects of the sustainable development goals will be addressed in future research. As per research limitations encountered, research findings show that social and environmental arenas are key priorities for participants. For instance, SDG 10 Reduced Inequalities was perceived as a social rather than an economic issue and aspects around refugees were the major concerns reported in this domain. Further research is needed on why these issues are or are not relevant for participants.

Acknowledgements This work was supported by the Japan Society for the Promotion of Science (JSPS) (Grant No. JP17777). One of the authors would like to thank an anonymous reviewer for substantive comments in the development of this manuscript.

\section{References}

Adara OA (1996) Strategies of environmental education in social studies in Nigeria by the year 2000. Environ Educ Res 2(2):237-246. https://doi.org/10.1080/1350462960020209

Adomßent M, Fischer D, Godemann J, Herzig C, Otte I, Rieckmann M, Timm J (2014) Emerging areas in research on higher education for sustainable development management education, sustainable consumption and perspectives from Central and Eastern Europe. J Clean Prod 62(2014):1-7 
Aikens K, McKenzie M, Vaughter P (2016) Environmental and sustainability education policy research: a systematic review of methodological and thematic trends. Environ Educ Res 22(3):333-359

Amatariyakul W, Tesaputa K (2009) Scenarios of Rajamangala University of Technology Isan in the next decade. Soc Sci 4:402-406

Arima A (2009) A plea for more education for sustainable development. Sustain Sci 4(1):3

Avila R, Leger N (2005) The future of higher education: a scenario evaluation of its prospects and challenges. iUniverse, New York

Azeiteiro UM, Bacelar-Nicolau P, Caetano FJ, Caeiro S (2015) Education for sustainable development through e-learning in higher education: experiences from Portugal. J Clean Prod 106:308-319

Azman N, Sirat M, Karim MA (2010) Building future scenarios for Malaysian universities. J Asian Publ Policy 3:86-99

Bak N (1995) Green doesn't always mean 'Go': possible tensions in the desirability and implementation of environmental education. Environ Educ Res 1(3):345-352. https://doi.org/10.1080/13504 62950010309

Barraza L, Duque-Aristizabal A, Rebolledo G (2003) Environmental education: from policy to practice. Environ Educ Res 9(3):347357. https://doi.org/10.1080/13504620303462

Barth M, Reickmann M (2012) Academic staff development as a catalyst for curriculum change towards education for sustainable development: an output perspective. J Clean Prod 26(2012):28-36

Blass E, Jasman A, Shelley S (2010) Visioning 2035: the future of the higher education sector in the UK. Futures 42(5):445-453. https ://doi.org/10.1016/j.futures.2009.11.029

Boron S, Murray KR, Thomson GB (2017) Sustainability education: towards total sustainability management teaching. In: Filho WL, Brandli L, Castro P, Newman J (eds), Handbook of theory and practice of sustainable development in higher education, vol 1, pp 37-52. https://doi.org/10.1007/978-3-319-47868-5

Braun V, Clarke V (2006) Using thematic analysis in psychology. Qual Res Psychol 3(2):77-101

Brundtland, G. H (1987) Our common future-The Brundtland Report. World Commission on Environment and Development

Caniglia G, John B, Bellina L, Lang DJ, Wiek A, Cohmer S, Laubichler MD (2018) The glocal curriculum: a model for transnational collaboration in higher education for sustainable development. J Clean Prod 171:368-376

Ceulemans K, De Prins M (2010) Teacher's manual and method for SD integration in curricula. J Clean Prod 18(7):645-651. https:// doi.org/10.1016/j.jclepro.2009.09.014

Comm CL, Mathaisel DFX (2008) Sustaining higher education using Wal-Mart's best supply chain management practices. Int J Sustain High Educ 2008(9):183-189

Conway M (2003) Scenarios and university planning. J Inst Res 13(2):34-40

Corcoran-Nantes Y, Roy S (2018) Gender, climate change, and sustainable development in Bangladesh. In: Balancing individualism and collectivism. Springer, Cham, pp 163-179

Cortese AD (2003) The critical role of higher education in creating a sustainable future. Plan High Educ 31(3):15-22

Dalhousie University (1991) Halifax declaration. Dalhousie University, Canada

Dlouhá J, Moldan B (2013) Sustainability in higher education: the central and eastern European case. In: Adomßent M, Otte I (eds) Higher education for sustainable development in Central and Eastern Europe. VAS, Bad Homburg, pp 13-32

Duderstadt JJ (2012) The future of the university: a perspective from the Oort cloud. Soc Res 79(3):579-600

Eisenhardt KM (1989) Building theories from case study research. Acad Manag Rev 14(4):532-550

Escobar A (1995) Encountering development: the making and unmaking of the third world. Princeton University Press, Princeton
Franco I (2014) Building sustainable communities: enhancing human capital in resource regions. PhD Dissertation. Brisbane, Australia: The University of Queensland

Frobel F (1826) On the education of man (die Menschenerziehung) Keilhau/Leipzig: Weinbrach

García-González E, Jiménez-Fontana R, Azcárate Goded P, Cardeñoso JM (2017) Inclusion of sustainability in university classrooms through methodology. In: Handbook of theory and practice of sustainable development in higher education. Springer, Cham, pp 3-19

González-Gaudiano EJ (2006) environmental education: a field in tension or in transition? Environ Educ Res 12(3-4):291-300. https:// doi.org/10.1080/13504620600799042

Hall TJK, Daneke GA, Lenox MJ (2010) Sustainable development and entrepreneurship: past contributions and future directions. J Business Ventures 25:439-448

Hashimshony R, Haina J (2006) Designing the university of the future. Plann High Educ 34(2):5

Hernandez PM, Vargas V, Paucar-Cáceres A (2018) Education for sustainable development: an exploratory survey of a sample of Latin American higher education institutions. In: Implementing sustainability in the curriculum of universities. Springer, Cham, pp 137-154

Holdsworth S, Wyborn C, Bekessy S, Thomas I (2008) Professional development for education for sustainability. Int J Sustain High Educ 2008(9):131-146

Inayatullah S, Ahmed S, Alam P, Davis S, Hashemi S (2013) Alternative scenarios for BRAC University. On the Horizon 21:275-285

Jóhannesson IÁ, Norðdahl K, Óskarsdóttir G, Pálsdóttir A, Pétursdóttir B (2011) Curriculum analysis and education for sustainable development in Iceland. Environ Educ Res 17(3):375-391. https ://doi.org/10.1080/13504622.2010.545872

Jongbloed B, Enders J, Salerno C (2008) Higher education and its communities: interconnections, interdependencies and a research agenda. High Educ 56(3):303-324

Kanie N, Biermann F (2017) Governing through goals. MIT press, Cambridge

Kivati G (2016) The Role of Kenya's formal higher education in sustainable development within the context of globalization. In Filho WL, Skanavis C, do Paço A, Rogers J, Kuznetsova O, Castro P (eds), Handbook of theory and practice of sustainable development in higher education, vol 2, pp 17-34. https://doi. org/10.1007/978-3-319-47889-0

Leal Filho W (2011) About the role of universities and their contribution to sustainable development. High Educ Policy 24(4):427-438

Lozano R, Ceulemans K, Alonso-Almeida M, Huisingh D, Lozano FJ, Waas T, Lambrechts W, Lukman R, Hugé J (2015) A review of commitment and implementation of sustainable development in higher education: results from a worldwide survey. J Clean Prod 108(2015):1-18

Lozano-Garcia, Huisingh (2006) Sustainability in higher education: what is happening? J Clean Prod 9(11):757-760

McNay I (1992) Visions of post-compulsory education, society for research into higher education. Open University Press, Maidenhead

Miller R (2003) The future of the tertiary education sector: scenarios for a learning society. In: a Paper presented at the OECD/Japan seminar (Tokyo, Japan)

Milutinović S, Nikolić V (2014) Rethinking higher education for sustainable development in Serbia: an assessment of Copernicus charter principles in current higher education practices. J Clean Prod 62(2014):107-113

Mochizuki Y, Fadeeva Z (2010) Competences for sustainable development and sustainability: significance and challenges for ESD. Int J Sustain High Educ 11(4):391-403 
Molderez I, Fonseca E (2018) The efficacy of real-world experiences and service learning for fostering competences for sustainable development in higher education. J Clean Prod 172:4397-4410

Naeem MA, Peach NW (2011) Promotion of sustainability in postgraduate education in the Asia Pacific region. Int J Sustain High Educ 2011(12):280-290

Ngoc UN, Schnitzer H (2009) Sustainable solutions for solid waste management in Southeast Asian countries. Waste Manag 29(6):1982-1995

O’Byrne D, Dripps W, Nicholas KA (2015) Teaching and learning sustainability: an assessment of the curriculum content and structure of sustainability degree programs in higher education. Sustain Sci 10(1):43-59

Okolie AC (2003) Producing knowledge for sustainable development in Africa: implications for higher education. High Educ 46(2):235-260

Puk T, Behm D (2003) The diluted curriculum: the role of government in developing ecological literacy as the first imperative in Ontario secondary schools. Can J Environ Educ 8:217-232

Regional Centres of Expertise on ESD Network (RCE Network) (2018) RCE Vision and mission. Retrieved from https://www.rcenetwork .org/portal/rce-vision-and-mission. Accessed 30 Jan 2018

Ritzen J (2006) Scenarios for higher education, 2020 or when will China Invade Iran? In: Keynote address during the OECD Ministerial Meeting. Paris

Ryan A, Tilbury D, Corcoran PB, Abe O, Nomura K (2010) Sustainability in higher education in the Asia-Pacific: developments, challenges and prospects. Int J Sustain High Educ 11(3):106-119

Saito O, Managi S, Kanie N, Kauffman J, Takeuchi K (2017) Sustainability Science and implementing the sustainable development goals. Sustain Sci 12(6):907-910

Shephard K (2015) Higher education for sustainable development. Palgrave Macmillan, UK

Singleton JR, Straits BC (2010) Approaches to social research, 5th edn. Oxford University Press, New York

Siraj-Blatchford J, Pramling-Samuelsson I (2016) Education for sustainable development in early childhood care and education: an introduction. In: International research on education for sustainable development in early childhood. Springer, Cham, pp 1-15

Sleurs W (2008) Competencies for ESD (education for sustainable development) teachers. A framework to integrate ESD in the curriculum of teacher training institutes. Comenius, 2.1 Project 118277 -CP-1-2004-BE-Comenius-C2.1. Available online at http://www.ensi.org

Snyder DP (2006) From higher education to longer, fuller, further education: the coming metamorphosis of the university. On the Horizon 14:43-61
Steinfeld JI, Mino T (2009) Education for sustainable development: the challenge of trans-disciplinarity. Sustain Sci 4(1):1

Stephens S (2011) Science or science fiction? The application of scenario techniques to the study of possible futures for learners in higher education. In: Fifth education in a changing environment conference book 2009: Critical Voices, Critical Times. Informing Science

Sultana P, Thompson PM (2007) Community based fisheries management and fisher livelihoods: Bangladesh case studies. Hum Ecol 35(5):527-546

UNESCO (2014) Roadmap for implementing the global action programme on education for sustainable development. UNESCO, Paris

UNESCO (2015) Guidelines on sustainability science in research and education. United Nations Educational, Scientific and Cultural Organization, Jakarta

UNESCO (2017) Practical guidelines to apply sustainability science frameworks: science-policy-society interface policy paper. United Nations Educational, Scientific and Cultural Organization, Jakarta

United Nations (2015) Transforming our World: the 2030 agenda for sustainable development. United Nations, New York

Vaughter P, Wright T, McKenzie M, Lidstone L (2013) Greening the ivory tower: a review of educational research on sustainability in post-secondary education. Sustainability 5(5):2252-2271

Vaughter P, McKenzie M, Lidstone L, Wright T (2016) Campus sustainability governance in Canada: a content analysis of postsecondary institutions' sustainability policies. Int J Sustain High Educ 17(1):16-39

Vincent-Lancrin S (2006) What is changing in academic research? Trends and futures scenarios. Eur J Educ 41(2):169-202

Yarime M, Trencher G, Mino T, Scholz RW, Olsson L, Ness B, Rotmans J (2012) Establishing sustainability science in higher education institutions: towards an integration of academic development, institutionalization, and stakeholder collaborations. Sustain Sci 7(1):101-113

Yin R (2003) Case study research: design and methods. Sage, Thousand Oaks

Yin R (2009) Case study: research design and methods (Fourth Edition ed. Vol. 5). SAGE Publications, Los Angeles

Yonehara A, Saito O, Hayashi K, Nagao M, Yanagisawa R, Matsuyama K (2017) The role of evaluation in achieving the SDGs. Sustain Sci (Spec Feature Sustain Sci Implement Sustain Dev Goals) 12:969-973 